\title{
Mass elevation effect and its forcing on timberline altitude
}

\author{
HAN Fang ${ }^{1}$, YAO Yonghui ${ }^{2}$, DAI Shibao ${ }^{1}$, WANG Chun ${ }^{1}$, SUN Ranhao ${ }^{3}$, \\ XU Juan ${ }^{4},{ }^{*}$ ZHANG Baiping ${ }^{2}$
}

1. Geographic Information and Tourism College, Chuzhou University, Chuzhou 239000, Anhui, China;

2. State Key Laboratory of Resource and Environment Information System, Institute of Geographic Sciences and Natural Resources Research, CAS, Beijing 100101, China;

3. State Key Laboratory of Urban and Regional Ecology, Research Center for Eco-Environmental Science, CAS, Beijing 100085, China;

4. Institute of Environment and Sustainable Development in Agriculture, Chinese Academy of Agricultural Sciences (CAAS), Beijing 100081, China

\begin{abstract}
The concept of mass elevation effect (massenerhebungseffect, MEE) was introduced by A. de Quervain about 100 years ago to account for the observed tendency for temperature-related parameters such as tree line and snowline to occur at higher elevations in the central Alps than on their outer margins. It also has been widely observed in other areas of the world, but there have not been significant, let alone quantitative, researches on this phenomenon. Especially, it has been usually completely neglected in developing fitting models of timberline elevation, with only longitude or latitude considered as impacting factors. This paper tries to quantify the contribution of MEE to timberline elevation. Considering that the more extensive the land mass and especially the higher the mountain base in the interior of land mass, the greater the mass elevation effect, this paper takes mountain base elevation (MBE) as the magnitude of MEE. We collect 157 data points of timberline elevation, and use their latitude, longitude and MBE as independent variables to build a multiple linear regression equation for timberline elevation in the southeastern Eurasian continent. The results turn out that the contribution of latitude, longitude and MBE to timberline altitude reach $25.11 \%$, $29.43 \%$, and $45.46 \%$, respectively. North of northern latitude $32^{\circ}$, the three factors' contribution amount to $48.50 \%, 24.04 \%$, and $27.46 \%$, respectively; to the south, their contribution is $13.01 \%, 48.33 \%$, and $38.66 \%$, respectively. This means that MBE, serving as a proxy indicator of MEE, is a significant factor determining the elevation of alpine timberline. Compared with other factors, it is more stable and independent in affecting timberline elevation. Of course, the magnitude of the actual MEE is certainly determined by other factors, including mountain area and height, the distance to the edge of a land mass, the structures of the mountains nearby. These factors need to be included in the study of MEE quantification in the future. This paper could help build up a high-accuracy and multi-scale elevation model for alpine timberline and even other altitudinal belts.
\end{abstract}

Keywords: mass elevation effect; mountain base elevation; altitudinal belts; quantification; Eurasia

Received: 2011-11-10 Accepted: 2011-12-09

Foundation: National Natural Science Foundation of China, No.41030528; No.40971064; Innovation Project of State Key Laboratory of Resources and Environmental Information System (LREIS)

Author: Han Fang, Ph.D, specialized in mountain altitudinal belts and mountain GIS research. E-mail: hanfah@163.com

"Corresponding author: Zhang Baiping, Ph.D and Professor, E-mail: zhangbp@1reis.ac.cn 


\section{Introduction}

Timberline, as the high altitude limit of forests, represents one of the most obvious vegetation boundaries and is thought to be sensitive to climate change. Generally, the altitude of alpine timberline declines from equator to the poles (Daubenmire et al., 1954; Tranquillini et al., 1979). On a global or continental scale, temperature is the final impact factor to determine timberline altitude (Holtmeier et al., 2005). High-altitude climatic tree lines are associated with a seasonal mean ground temperature of $6.7^{\circ} \mathrm{C}$ (Körner et al., 2004). Jobbagy \& Jackson (2000) introduced a continentality index in combination with annual mean temperatures to predict treeline altitude. Many other studies have been done to explore the cause for the transition from forest to alpine shrub and grassland (Miehe et al., 1994; Körner et al., 1998; Alvarea-Uria et al., 2007). However, many difficulties arise to explain timberline elevation with temperature. The number of meteorological stations in remote areas is quite limited, and almost all of the meteorological stations are far away from the timberlines; any extrapolation from data recorded at meteorological stations, carries with it the uncertainty to what extent they match actual temperatures experienced by trees (Körner et al., 2004); besides temperature, precipitation, wind and some other environment factors can affect timberline on different scales and to varied extents; the effect of such factors could mutually compensate on a certain extent. Hence, the relationships between timberline elevation and temperature are very complicated. It is impossible to find a constant critical value of temperature which perfectly matches timberline elevation. Therefore, it's far from enough to consider only temperature or any other single factor when exploring timberline's altitudinal distribution.

On a global or regional scale, climate is mostly related with geographical position. Since the 1910s, many fitting models have been developed for the elevation of altitudinal belts, especially alpine timberline, by relating the elevation of altitudinal belts to geographical location with latitude as a surrogate of temperature and longitude as a surrogate of precipitation (Sapozhnikov et al., 1916; Hermes et al., 1955; Jiang et al., 1987; 1993; Ozenda et al., 1989; Körner et al., 1998; Zhang et al., 2006; Zheng et al., 1996). However, most of these models involve small scales and usually could not be applied to other regions; while those established for the Northern Hemisphere or the whole globe are of very low precision. For instance, the altitude of timberline around equator should be $5068 \mathrm{~m}$ if estimated in terms of the model for Ural Mountains (Malyshev et al., 1993), whereas it is actually about $3500 \mathrm{~m}$ in Mt. Kenya and Kilimanjaro in Africa (Hedberg et al., 1964).

It has been recognized that timberline heterogeneity increases from globe to regional and smaller scales, and assessment of timberline sensitivity at the landscape and local scales requires a more complex approach than at the global scale (Holtmeier et al., 2005). Large mountain massifs have a positive effect on timberline (Holtmeier et al., 2009; Leonelli et al., 2009). This phenomenon was introduced by A. de Quervain in 1904 as "mass elevation effect (Massenerhebungseffect, short as MEE in the following text)" to account for the observed tendency for temperature-related parameters such as treeline and snowline to occur at higher elevations in the central Alps than on their outer margins (Barry et al., 1992; Quervain et al., 1904; Schroeter et al., 1908). The occurrence of physiognomically and sometimes floristically similar vegetation types at higher altitudes on large mountain masses than 
on small isolated peaks especially those in or near the sea are also regarded as MEE in general, and this phenomenon has been discovered and reported in other places of the world afterwards (Barry et al., 1992; Aas et al., 1996; Leuschner et al., 1996; Fang et al., 1999; Wang et al., 2004; Flenley et al., 1995; 2007).

Geographers and botanists have been attempting to explain this phenomenon from different angles. Flohn (1953) proposed that elevated plateau surfaces, such as the Tibetan Plateau and the Altiplano in South American, are warmer in summer than the adjacent free air as a result of the altitudinal increase in solar radiation and the relative constancy of the effective infra-red radiation with height. This point of view was confirmed by later researches (Yeh et al., 1982; Chen et al., 1985). Grubb (1971) attempted to account for the phenomenon from a microcosmic view: the high frequency of fog in tropic mountainous regions reduced the nutritive materials in soil, and restrained the growth of vegetations on the mountains in tropics. Therefore, there is a tendency for physiognomically and sometimes floristically similar vegetation types to appear on lower altitudes in tropic mountains. Barry (1992) analyzed MEE of the Alps and pointed out that the vegetation boundaries extending to higher elevations in the central Alps are related primarily to reduced snow cover duration, greater radiation income, and longer growing season. Flenley (2007) proposed a hypothesis that MEE could partly be the result of a high dose of UV-B due to reflection from clouds.

MEE leads to great differences in the distribution of a certain altitudinal belt in different mountains at same latitude or longitude. For example, alpine timberline climbs up to $4600 \mathrm{~m}$ in the southeastern Tibet (Troll et al., 1972), while, only $650 \mathrm{~km}$ to the east, it is merely $3600 \mathrm{~m}$ in Balang Mountains (Wang et al., 2004), a difference of $1000 \mathrm{~m}$. Investigation on the distribution of alpine vegetation and timberline on island shows that there are few island mountains high enough to have timberline, and the timberline on islands is about 1000-2000 $\mathrm{m}$ lower than in the inland mountains (Leuschner et al., 1996). The distribution pattern of Chinese beech (Fagus L.) is closely related with macro-topography in China (Fang et al., 1999).

As Flenley (2007) stated, the full explanation of MEE will be a multivariate one, and some factors may be more important in one location, while other factors may dominate elsewhere. These factors may include mountain height, mountain base elevation (MBE), mountain area, distance to the nearest periphery of high land mass, landform conditions in the surroundings. It is really a challenge to accurately measure or quantify MEE by considering all of these factors. However, we could start this campaign with a major factor $-\mathrm{MBE}$. It usually rises from outsides towards the inner parts of a land mass, just as expected of MEE. As a consequence, to a great extent, MBE could be regarded as MEE. In this paper, it is used to explore the contribution of MEE to timberline elevation.

\section{Method and data}

Researchers have proved that the elevation of timberline could be linearly related to latitude and longitude in temperate and boreal regions (Li et al., 1979; Ohsawa et al., 1990; Zheng et al., 1996). As shown above, it might also be related with MEE or MBE. Therefore, we can use latitude, longitude and MBE as independent variables to build a multiple linear regression equation for timberline altitude, and then calculate the contribution rate of each factor 
to the timberline altitude. The model is:

$$
y=\mathrm{a} x_{1}+\mathrm{b} x_{2}+\mathrm{c} x_{3}+\mathrm{d}
$$

where $y=$ timberline altitude, $x_{1}=$ latitude, $x_{2}=$ longitude, $x_{3}=$ MBE. a, $\mathrm{b}$ and $\mathrm{c}$ are coefficients of independent variables, and $\mathrm{d}$ is constant term.

We collected a total of 157 timberline data, including latitude, longitude and MBE, from the southeastern Eurasian continent (south of $45^{\circ} 18^{\prime} \mathrm{N}$, east of $65^{\circ} 33^{\prime} \mathrm{E}$ ), as shown in Figure 1. The collection of timberline data follows such principles: (1) if closed forests' altitude is used as timberline elevation, the data are directly adopted; (2) if timberline ecotone altitude was expressed with an interval value, and it is specified that the lower limit is closed forest altitude and the upper limit is treeline altitude, then the upper limit and the lower limit is treated as treeline altitude and timberline altitude, respectively; (3) if the timberline ecotone altitude was expressed with an interval value but without specific description, we will take the middle value as the timberline altitude; (4)if the altitudinal difference between mountain top and timberline altitude is less than $100 \mathrm{~m}$, the data are excluded; (5) if data of a certain point appeared in more than one literatures, we make a cross validation to assure its correction.

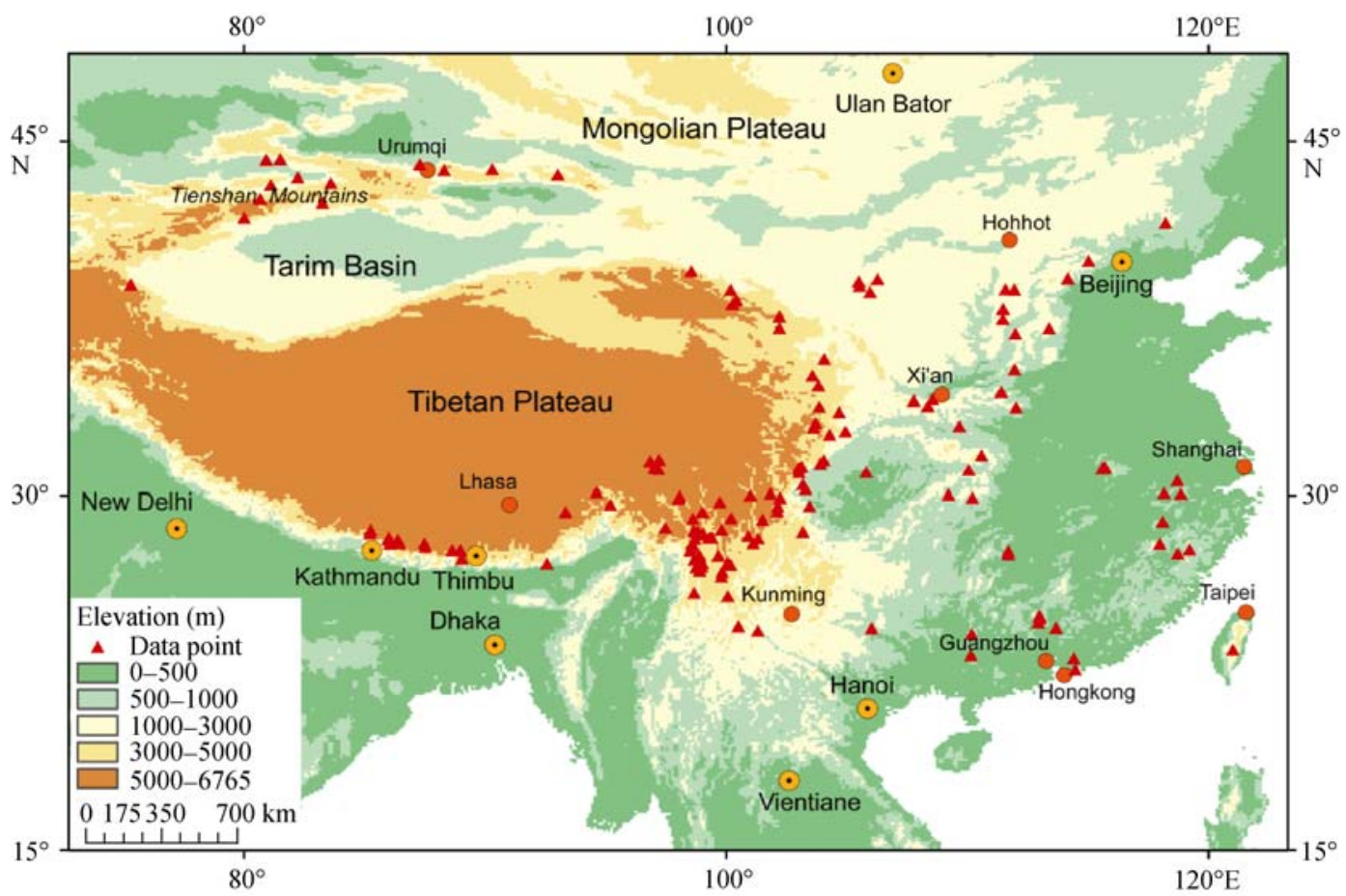

Figure 1 Location of 157 timberline data points in the southeastern Eurasian continent

\section{Study area}

The study area faces the Pacific Ocean on the east, and Indian Ocean on the south, with the immense Tibetan Plateau in the center. In this region, timberline could reach as high as 4600 $\mathrm{m}$ (the highest timberline in the world, or at least in the Northern Hemisphere) in the south- 
east of the Tibetan Plateau, and can fall to $900 \mathrm{~m}$ in some low-lying mountains of southeastern China.

We have noted that the timberline altitude varies quite differently from north to south of $32^{\circ} \mathrm{N}$ (Figure 2). To the north, it has a typical negative correlation with latitude. But to the south, almost no general patterns take form. Therefore, we divide the data samples into two groups so as to see what happens in the northern and southern areas separately.

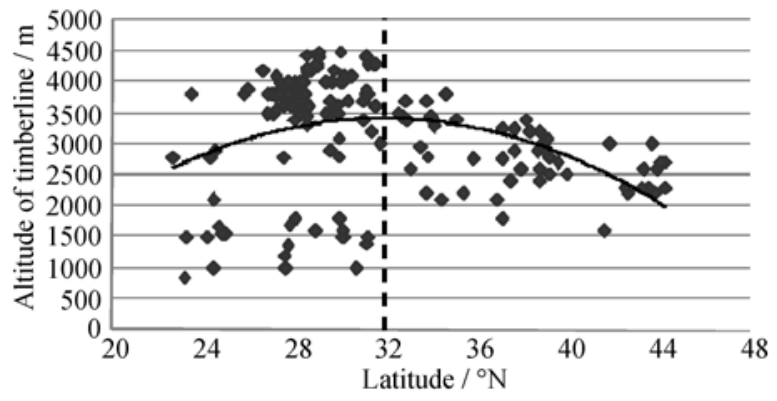

Figure 2 Latitudinal pattern of timberline altitude in southeast of Eurasia

\section{Results and analysis}

Correlation analysis indicates that, timberline altitude is significantly correlated with latitude, longitude, and MBE, respectively (Table 1).

Table 1 The correlation of independent and dependent variables in the model for timberline distribution

\begin{tabular}{cccccc}
\hline & & Latitude & Longitude & MBE & Timberline altitude \\
\hline \multirow{2}{*}{ Latitude } & Pearson Correlation & 1 & $-0.231\left(^{* *}\right)$ & -0.001 & $-0.208(* *)$ \\
& Sig. (2-tailed) & & 0.004 & 0.985 & 0.009 \\
& Sample number & 157 & 157 & 157 & 157 \\
& Pearson Correlation & $-0.231(* *)$ & 1 & $-0.390(* *)$ & $-0.470(* *)$ \\
Longitude & Sig. (2-tailed) & 0.004 & & 0.000 & 0.000 \\
& Sample number & 157 & 157 & 157 & 157 \\
& Pearson Correlation & -0.001 & $-0.390(* *)$ & 1 & $0.647(* *)$ \\
MBE & Sig. (2-tailed) & 0.985 & 0.000 & & 0.000 \\
& Sample number & 157 & 157 & 157 & 157 \\
Timberline & Pearson Correlation & $-0.208(* *)$ & $-0.470(* *)$ & $0.647(* *)$ & 1 \\
altitude & Sig. (2-tailed) & 0.000 & 0.000 & 0.000 & 157 \\
& Sample number & 157 & 157 & 157 \\
\hline
\end{tabular}

**. Correlation is signification at the 0.01 level (2-tailed).

Coefficient of determination $\left(\mathrm{R}^{2}\right)$ and F-value of analysis of variance (ANOVA) (see Table 2) indicates that the multiple linear regression (MLR) equation could be adequately used to fit the distribution of timberline. T-test of regression coefficient shows that the three independent variables have significant correlations with the distribution of timberline. Supposing that the combined effect of latitude, longitude and $\mathrm{MBE}$ to the distribution of timberline is $100 \%$, we can figure out their contributing rates, respectively, $25.11 \%, 29.43 \%$, and $45.46 \%$ based on their Standardized Coefficients (Beta). It can be seen that, for the whole 
Table 2 Multiple linear regression model summary, ANOVA, regression coefficients and their test of significance for the samples in the southeastern Eurasia

\begin{tabular}{|c|c|c|c|c|c|c|c|}
\hline & $\begin{array}{c}\text { Coefficient of } \\
\text { Determination }\left(R^{2}\right)\end{array}$ & $\mathrm{F}$ & $\begin{array}{l}\text { Unstandardized } \\
\text { Coefficients(B) }\end{array}$ & $\begin{array}{l}\text { Standardized Coef- } \\
\text { ficients (Beta) }\end{array}$ & $\begin{array}{l}\text { Contribution } \\
\text { Rate }\end{array}$ & $\mathrm{t}$ & Sig. \\
\hline Constant Term & \multirow{4}{*}{0.550} & \multirow{4}{*}{$\begin{array}{c}62.276 \\
(\mathrm{P}=0.000)\end{array}$} & 7169.692 & & & 9.320 & 0.000 \\
\hline Latitude & & & -48.572 & -0.285 & $25.11 \%$ & -5.076 & 0.000 \\
\hline Longitude & & & -32.146 & -0.334 & $29.43 \%$ & -5.493 & 0.000 \\
\hline MBE & & & 0.595 & 0.516 & $45.46 \%$ & 8.712 & 0.000 \\
\hline
\end{tabular}

region, MBE contributes the most to the altitudinal distribution of timberline, longitude next, and latitude the least.

North of $32^{\circ}$ northern latitude

As Table 3 shows, the MLR equation also fits the distribution of timberline in the northern areas. T-test of regression coefficient indicates that latitude and MBE have significant correlations with the distribution of timberline, only longitude at a significant level less than 0.05. Contributing rates indicate that latitude is the most important determining factor of timberline elevation (contributing rate is $48.50 \%$ ), MBE the second (27.46\%), and longitude the least $(24.04 \%)$. The northern area is far away from the sea, characterized by continental climate. The effect of solar radiation, represented by latitude, is relatively high; while the effect of moisture, represented by longitude, is weakened. Consequently, latitude becomes the dominant factor controlling the elevation of alpine timberline; MBE takes the second place; and longitude the last.

Table 3 Multiple linear regression model summary, ANOVA, regression coefficients and their test of significance for the samples in the north of $32^{\circ} \mathrm{N}$

\begin{tabular}{lccccccc}
\hline & $\begin{array}{c}\text { Coefficient of de- } \\
\left.\text { termination( } \mathrm{R}^{2}\right)\end{array}$ & $\mathrm{F}$ & $\begin{array}{c}\text { Unstandardized } \\
\text { coefficients (B) }\end{array}$ & $\begin{array}{c}\text { Standardized coef- } \\
\text { ficients (Beta) }\end{array}$ & $\begin{array}{c}\text { Contribution } \\
\text { rate (\%) }\end{array}$ & $\mathrm{t}$ & Sig. \\
\hline Constant term & & & 7693.330 & & & 5.934 & 0.000 \\
Latitude & 0.505 & 16.003 & -96.573 & -0.694 & 48.50 & -4.996 & 0.000 \\
Longitude & & $(\mathrm{P}=0.000)$ & -15.655 & -0.344 & 24.04 & -2.438 & 0.019 \\
MBE & & & 0.302 & 0.393 & 27.46 & 3.693 & 0.000 \\
\hline
\end{tabular}

South of $32^{\circ}$ Northern Latitude

As shown in Table 4, the coefficient of determination $\left(\mathrm{R}^{2}\right)$ of our regression equation is as high as 0.690 . But the contributing rates of the three factors change greatly: longitude (stand for moist variation) becomes the leading factor (48.33\%), MBE the second $(38.66 \%)$, and

Table 4 Multiple linear regression model summary, ANOVA, regression coefficients and their test of significance for the samples in the south of $32^{\circ} \mathrm{N}$

\begin{tabular}{|c|c|c|c|c|c|c|c|}
\hline & $\begin{array}{c}\text { Coefficient of } \\
\text { determination }\left(\mathrm{R}^{2}\right)\end{array}$ & $\mathrm{F}$ & $\begin{array}{l}\text { Unstandardized } \\
\text { coefficients (B) }\end{array}$ & $\begin{array}{l}\text { Standardized coef- } \\
\text { ficients (Beta) }\end{array}$ & $\begin{array}{l}\text { Contribution } \\
\text { rate }(\%)\end{array}$ & $\mathrm{t}$ & Sig. \\
\hline Constant term & \multirow{3}{*}{0.690} & \multirow{4}{*}{$\begin{array}{c}75.754 \\
(\mathrm{P}=0.000)\end{array}$} & 6899.984 & & & 6.126 & 0.000 \\
\hline Latitude & & & 66.305 & 0.136 & 13.01 & 2.397 & 0.018 \\
\hline Longitude & & & -60.042 & -0.505 & 48.33 & -7.847 & 0.000 \\
\hline MBE & & & 0.485 & 0.404 & 38.66 & 6.131 & 0.000 \\
\hline
\end{tabular}


latitude the least (only 13.01\%). This is understandable. The southern area is close to the sea, strongly influenced by oceanic climate. But the central parts are high mountains and plateaus, receiving much less precipitation. So, the moisture condition changes greatly from east to west. As a result, the effect of longitude is relatively strong, MEE (simply MBE) also high, but the effect of latitude weakens.

\section{Conclusions and discussion}

(1) On continental or regional scales, timberline altitude is related both to geographical location (latitude and longitude) and to MEE; and the relative effect of these factors is strongly scale-dependent and region-dependent.

(2) MEE significantly impacts the elevation of timberline, averagely stronger than latitude and longitude. Especially, compared with other driving factors, it is relatively steady and independent. On the other hand, the effects of latitude and longitude are complementary: when one increases, the other decreases. This means that we should take MEE into account when developing elevation model of alpine timberline.

(3) MBE can only represent MEE to some extent. Many other factors are also responsible for the magnitude of MEE, including mountain height, mountain area, distance to the nearest periphery of high land mass, landform conditions in the surroundings. So, this paper is only the first step toward quantifying MEE. In future studies, these factors should be taken into consideration.

\section{References}

Aas B, Faarlund T, 1996. The present and the Holocene birth belt in Norway. Paläo-klimaforschung, 20 : 18-24.

Alvarez-Uria P, Körner C, 2007. Low temperature limits of root growth in deciduous and evergreen temperate tree species. Functional Ecology, 21(2): 211-218.

Barry R G, 1992. Mountain Weather and Climate. London and New York: Routledge, 57.

Chen L X, Reiter E R, Feng Z Q, 1985. The atmospheric heat-source over the Tibetan Plateau - May - August 1979. Monthly Weather Review, 113(10): 1771-1790.

Daubenmire R, 1954. Alpine timberline in the Americas and their interpretation. Bulter Univ. Bot. Stud., (11): 119-136.

Fang J Y, Chen Z H, Cun H T, 2004. Ecological characteristics of mountains and research issues of mountain ecology. Biodiversity Science, 12(1): 10-19. (in Chinese)

Fang J Y, Liu G H, Guo Q H, 1999. Distribution patterns of Chinese beech (Fagus L.) species in relation to topography. Acta Botanica Sinica, 41(7): 766-774. (in Chinese)

Flenley J, 2007. Ultraviolet insolation and the tropical rainforest: Altitudinal variations, Quaternary and recent change, extinctions, and biodiversity. In: Flenley J R, Bush M B. Tropical Rainforest Responses to Climatic Change. UK: Jointly published with Praxis Publishing, 219-235.

Flenley J R, 1995. Cloud forest, the Massenerhebung effect, and ultraviolet insolation. Tropical Montane Cloud Forests, 110: 150-155.

Flohn H, 1953. Hochgebirge und allgemeine Zirkulation. II. Gebirge als Wärmequellen. Archiv fur Meteorologie, Geophsik und Bioklimatologie, 5A: 265-279.

Grubb P J, 1971. Interpretation of Massenerhebung effect on tropical mountains. Nature, 229(5279): 44-45.

Hedberg O, 1964. Études écologiques de la flore afroalpine. Bulletin de la Société Royale Botanique de Belgique, 97: 5-18.

Hermes K, 1955. Die Lage der oberen Waldgrenze in den Gebirgender der Erde und ihr Abstand zur Schneegrenze. 
Kölner Geo-graphische Arbeiten, 5: 115.

Holtmeier F K, 2009. Mountain timberlines ecology, patchiness, and dynamics. Advances in Global Change Research, 36: 1-437.

Holtmeier F K, Broll G, 2005. Sensitivity and response of Northern Hemisphere altitudinal and polar treelines to environmental change at landscape and local scales. Global Ecology and Biogeography, 14(5): 395-410.

Jobbagy E G, Jackson R B, 2000. Global controls of forest line elevation in the Northern and Southern Hemispheres. Global Ecology and Biogeography, 9(3): 253-268.

Körner C, 1998. A re-assessment of high elevation treeline positions and their explanation. Oecologia, 115(4): 445-459.

Körner J P, 2004. A world-wide study of high altitude treeline temperatures. Journal of Biogeography, 31(5): $713-732$.

Leonelli C, 2009. Detecting climatic treelines in the Italian Alps: The influence of geomorphological factors and human impacts. Physical Geography, 30(4): 338-352.

Leuschner C, 1996. Timberline and alpine vegetation on the tropical and warm-temperate oceanic islands of the world: Elevation, structure and floristics. Vegetation, 123(2): 193-206.

Li W H, Zhou P C, 1979. Study on the distribution of the spruce-fir forest on Eurasia and its modeling. Natural Resources, 1(1): 21-34. (in Chinese)

Malyshev L, 1993. Levels of the upper forest boundary in northern Asia. Vegetation, 109(2): 175-186.

Martin P S, 1963. Geochronology of pluvial lake cochise, southern Arizona. II. Pollen analysis of a 42-meter core. Ecology, 44(3): 436-444.

Miehe S, 1994. Humidity-dependent sequences of altitudinal vegetation belts in the northwestern Karakorum. In: Pan Y S, Zheng D, Zhang Q S. Proceedings of International Symposium on the Karakoram Mountains. Beijing: China Meteorological Press, 347-363.

Ohsawa M, 1990. An interpretation of latitudinal patterns of forest limits in South and East Asia. Journal of Ecology, 78(2): 326-339.

Ozenda P, 1989. The vertical displacement of the stages of vegetation as a function of the latitude: A simple model and its limits. Bulletin de la Societe Geologique de France, 5(3): 535-540.

Quervain A D, 1904. Die Hebung der atmosphärischen lsothermenin der Schweizer Alpen und ihre Beziehung zu deren Höhengrenzen. Gerlands Beitrage zur Geophysik, 6: 481-533.

Sapozhnikov V V, 1916. Near the upper frontier of vegetation. In: Collected Papers Dedicated to K. A. Timiryazev by His Pupils. Moscow, 85-102.

Schroeter C, 1908. Das pflanzenleben der Alpen: Eine schilderung der hochgebrigsflora. Verlag von Albert Raustein, Zurich, Switzerland: Verlag von Albert Raustein.

Tan J, Zhang B P, Sun R H, 2008. A framework for digitally integrating mountain altitudinal belt spectra in the Eurasian Continent. Journal of Mountain Science, 26(6): 641-651. (in Chinese)

Tranquillini W, 1985. Physiological Ecology of the Alpine Timberline: Tree Existence at High Special Reference to the European Alps. Berlin and New York: Springer-Verlag, 1-12, 118-148.

Troll C, 1972. Geoecology of the world-wide different of high-mountain ecosystems. In: Troll C ed. Geoecology of the High Mountain Regions of Eurasia. Wiesbaden, Franz Steiner Verlag Gmbh., 1-16.

Wang X P, Wang Z H, Fang J Y, 2004. Mountain ranges and peaks in China. Chinese Biodiversity, 12(1): $206-212$. (in Chinese)

Yeh T, 1982. Some aspects of the thermal influences of the Qinghai-Tibetan Plateau on the atmospheric circulation. Meteorology and Atmospheric Physics, 31(3): 205-220.

Zhang B P, Wu H Z, Xiao F, 2006. Integration of data on Chinese mountains into a digital altitudinal belt system. Mountain Research and Development, 26(2): 163-171.

Zheng Y C, Wang M J, 1996. A study on the mathematical model of the vertical distribution of natural belts in the southeastern part of the Qinghai-Tibet Plateau and their ecological analysis. Journal of Natural Resources, 11(3): 249-255. (in Chinese) 